\title{
PRÁTICAS E FERRAMENTAS UTILIZADAS PARA A GESTÃO DO CONHECIMENTO EM DEPARTAMENTOS DE P\&D DE EMPRESAS BRASILEIRAS DE GRANDE PORTE
}

\section{PRACTICES AND TOOLS APPLIED TO KNOWLEDGE MANAGEMENT IN R\&D DEPARTMENTS OF BRAZILIAN LARGE COMPANIES}

\author{
Alexandre de Almeida Guimarães ${ }^{1}$; José Eduardo Gonçalves Lamas ${ }^{2}$, Paulo Tadeu de Mello \\ Lourenção ${ }^{3}$; Pedro Geraldo Boscolo ${ }^{4}$; Isak Kruglianskas ${ }^{5}$ \\ ${ }^{1}$ General Motors do Brasil Ltda. - GMB - São Caetano do Sul - Brasil \\ alexandre.guimaraes@gm.com \\ ${ }^{2}$ Empresa Brasileira de Aeronáutica S. A. - EMBRAER - São José dos Campos - Brasil \\ jose.lamas@embraer.com.br \\ ${ }^{3}$ Empresa Brasileira de Aeronáutica S. A. - EMBRAER - São José dos Campos - Brasil \\ paulo.lourencao@embraer.com.br \\ ${ }^{4}$ Quattor Petroquímica S.A. - QUATTOR - São Paulo - Brasil \\ pedro.boscolo@quattor.com.br \\ ${ }^{5}$ Faculdade de Economia e Administração - FEA/USP - São Paulo - Brasil \\ ikruglia@usp.br
}

\begin{abstract}
Resumo
No contexto atual dos negócios globalizados, o gerenciamento eficaz de recursos intangíveis tais como o conhecimento, passa a ser diferencial competitivo. Tanto indústrias quanto organizações de pesquisa e desenvolvimento têm obtido resultados interessantes através da aplicação de princípios de Gestão do Conhecimento (GC) para otimizar o desenvolvimento de novos produtos e processos. Este trabalho tem como objetivo comparar ferramentas e práticas de GC citadas na literatura com as utilizadas nas áreas de $P \& D$ de três empresas de grande porte que atuam no Brasil. Dos referenciais teóricos foram identificadas quatro categorias de práticas e ferramentas de GC: a) Tecnologia da Informação (TI); b) Compartilhamento do Conhecimento; c) Processos, Estruturas e Valores e d) Gestão de Pessoas. Foram entrevistados 16 profissionais das áreas de P\&D e as informações obtidas foram analisadas utilizando as mesmas categorias identificadas na literatura. Como resultado, destaca-se que grande parte das ferramentas e práticas de GC nos departamentos de P\&D parece ter como base a tecnologia da informação e o compartilhamento do conhecimento. Aspectos ligados à cultura organizacional e gestão de pessoas, embora reconhecidamente importantes na questão $G C$, foram pouco lembrados pelos entrevistados.
\end{abstract}

Palavras-chave: gestão do conhecimento, práticas, ferramentas, P\&D. 


\section{Introdução}

A partir da segunda metade do século XX, com maior ênfase a partir dos anos 70, certas tendências econômicas, sociais e tecnológicas têm sido observadas. Entre elas podem ser citadas: crescente globalização, rápida evolução dos meios de comunicação, barateamento e universalização da informação e a diminuição do ciclo de vida de produtos. Estas tendências têm levado as empresas a focarem mais e mais recursos para diferenciar seus produtos e serviços visando à sobrevivência em um mercado cada vez mais competitivo (PRUSAK, 2001; TERRA E GORDON, 2002). Neste cenário, as organizações com maior capacidade de aprender e colocar o aprendizado a serviço da inovação tem maior possibilidade de se perpetuar (TERRA, 2000 e AMBRECHT et al, 2001).

Os modelos de gerenciamento já consagrados e amplamente usados desde o início do século passado, focados basicamente na administração de recursos tangíveis, como capital e bens de produção, não têm a mesma eficácia quando usados para gerenciar recursos intangíveis, como o conhecimento. Assim, torna-se necessária uma nova forma de gestão, com outras prioridades e perspectivas para se criar riqueza no século XXI (PRUSAK, 2006).

Segundo Ambrecht et al. (2001), neste mundo turbulento e em rápida transformação em que vivemos, cada organização enfrenta o desafio de como melhor gerenciar seus ativos de conhecimento para gerar valor para o mercado e obter vantagem competitiva. Tal vantagem é decorrente de capacidades especiais que são raras, valiosas, insubstituíveis e custosas de imitar. Historicamente, o foco sempre esteve voltado às capacidades relacionadas aos ativos tangíveis. Atualmente, o conhecimento é largamente reconhecido como a principal fonte de vantagem competitiva, sendo que os ativos tangíveis representam a manifestação física de, apenas, parte deste conhecimento. Segundo Prusak (2006), esta mudança de foco pode ser evidenciada pelo volume de recursos aplicados - isto é: atualmente se gasta tanto com tangíveis quanto com intangíveis. Há 10 anos a proporção era de quatro para um.

Ambrecht et al. (2001) afirmam que algumas organizações de pesquisa e desenvolvimento (P\&D) têm obtido significantes resultados através da aplicação de princípios de GC para promover o fluxo de conhecimento interno e de informações externas. Além disso, ressaltam que a função P\&D necessita de um foco diferente daquele demandado por outras áreas, especificamente no que tange o desenvolvimento de livre acesso ao conhecimento tácito das pessoas. Destacam, ainda, que o campo da gestão do conhecimento recebe crescente atenção de empresas e universidades, uma vez que as organizações estão se desdobrando para gerenciar seu conhecimento de forma mais proativa e estratégica. 


\subsection{Objetivo}

O presente trabalho apresenta os resultados de uma pesquisa realizada com o objetivo comparar as ferramentas e práticas de GC mencionadas na literatura com aquelas utilizadas nas áreas de P\&D de três empresas de grande porte que atuam no Brasil. Para tanto, foram estabelecidos critérios de classificação das práticas e ferramentas, procurando facilitar os processos de comparação e análise. A partir destes resultados foi possível inferir que estas ferramentas e práticas também podem ser úteis para outras empresas que desenvolvem produtos de grande conteúdo tecnológico, quando da estruturação de suas iniciativas de GC.

\subsection{Descrição}

Este trabalho está estruturado em 6 capítulos. No capítulo 2, Fundamentos Teóricos, são apresentados conceitos relacionados à pesquisa e desenvolvimento e gestão do conhecimento. $\mathrm{O}$ capítulo 3 descreve a metodologia utilizada para o planejamento, execução e análise da pesquisa de campo. Nos capítulos 4 e 5 são apresentados e discutidos os resultados da pesquisa que foi realizada em 3 empresas que desenvolvem e comercializam produtos de grande conteúdo tecnológico e que têm em sua estrutura centros dedicados para o desenvolvimento de novas tecnologias e novos produtos. Finalmente, no capítulo 6, são resumidos os principais resultados e são sugeridas ações de continuidade para a pesquisa.

\section{Fundamentos Teóricos}

Inicialmente são apresentados alguns conceitos e definições importantes para o desenvolvimento do trabalho.

Tecnologia - Aplicação do conhecimento científico e de engenharia para a obtenção de um resultado prático. É o processo que capacita uma empresa a dizer "Nós sabemos como aplicar ciência/engenharia a..." de uma forma que esclareça o que a tecnologia faz para o negócio em vez de apenas declarar o que ela é. Por esta definição, a ciência e a engenharia estão embutidas no processo ou produto através da tecnologia (ROUSSEL et al., 1992).

Pesquisa - Para o acadêmico e para aqueles que trabalham em institutos de pesquisa, significa uma abordagem disciplinada à revelação de novos conhecimentos sobre o universo. $\mathrm{O}$ objetivo da pesquisa é promover o conhecimento e o entendimento, e as fronteiras da pesquisa são ilimitadas (ROUSSEL et al., 1992). 
A pesquisa industrial partilha sua busca de novos conhecimentos, mas suas metas são, em geral, diferentes daquelas do pesquisador acadêmico. Na indústria, o objetivo da pesquisa é o conhecimento aplicável às necessidades comerciais da empresa, que a capacite a participar da vanguarda da nova tecnologia ou a lançar as bases para o desenvolvimento de novos produtos ou processos.

Ainda que não haja demarcação precisa entre as definições de pesquisa e desenvolvimento, uma distinção ampla pode ser sugerida. Se o propósito da pesquisa é desenvolver novos conhecimentos, o propósito do desenvolvimento é aplicar conhecimento científico ou de engenharia. No caso geral, o desenvolvimento procura transformar conhecimentos em produto ou processos, através de uma série de etapas definidas, a fim de prová-los, refiná-los e prepará-los para a aplicação comercial.

A gestão do processo de inovação usualmente é composta das seguintes fases (TIDD et al., 2001):

a) Processamento de informações (avaliação do ambiente, buscando informações de relevância tecnológica);

b) Análise estratégica (avaliação das informações versus possibilidades de ação; verificação de alinhamento com objetivos corporativos; verificação de existência de competências essenciais; avaliação de custos e benefícios; priorização/ seleção e finalmente comprometimento de recursos);

c) Alocação de recursos (definição de soluções; desenvolvimento interno; aquisição externa; transferência de tecnologia);

d) Implementação (desenvolvimento do produto e do mercado; desenvolvimento do processo; lançamento do produto/serviço; organização do apoio ao cliente);

e) Feedback (aprendizagem e inovação).

\subsection{Gestão do Conhecimento}

Esta parte do trabalho visa apresentar ao leitor alguns modelos sobre o tema Gestão do Conhecimento propostos na literatura, cujas idéias foram adaptadas para a construção da taxonomia adotada para classificar as práticas e ferramentas de GC.

Nonaka e Takeuschi (1995) foram dos primeiros autores a apresentarem modelos para a descrição e análise dos processos relacionados ao conhecimento empresarial. São seminais as idéias de tipos de conhecimento: tácito (subjetivo, no âmbito da pessoa) e explícito (objetivo, no âmbito 
dos documentos). Segundo os autores, há quatro modos básicos de conversão do conhecimento: socialização, externalização, combinação e internalização, conforme ilustrado na figura 1.

Figura 1 - Espiral do conhecimento

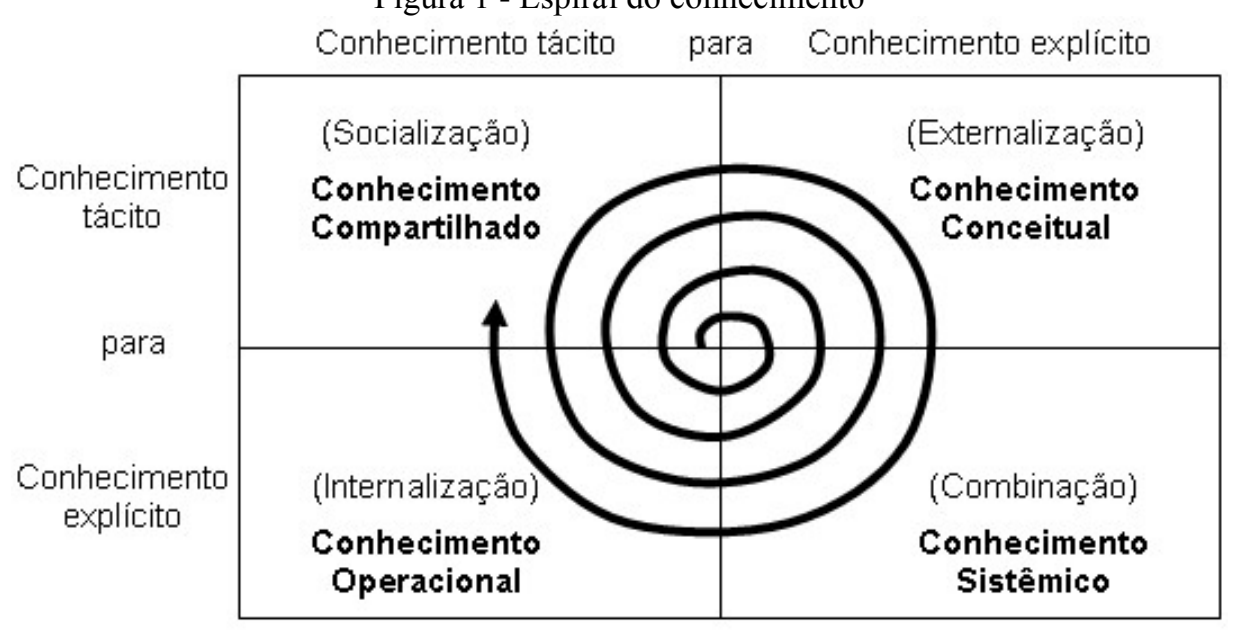

Fonte: Adaptado de Nonaka \& Takeuchi (1997)

Tendo em mente o objetivo deste trabalho, chamam a atenção as práticas e ferramentas de transmissão e conversão conhecimento, com aspectos ligados a pessoas e processos e infraestrutura.

Terra (2000) apresenta um modelo de GC com sete dimensões da prática empresarial: estratégia, cultura, estrutura organizacional, políticas de $\mathrm{RH}$, tecnologia da informação (TI), resultados e aprendizagem do ambiente, apresentado esquematicamente na figura 2.

Figura 2 - Planos e dimensões da gestão do conhecimento.

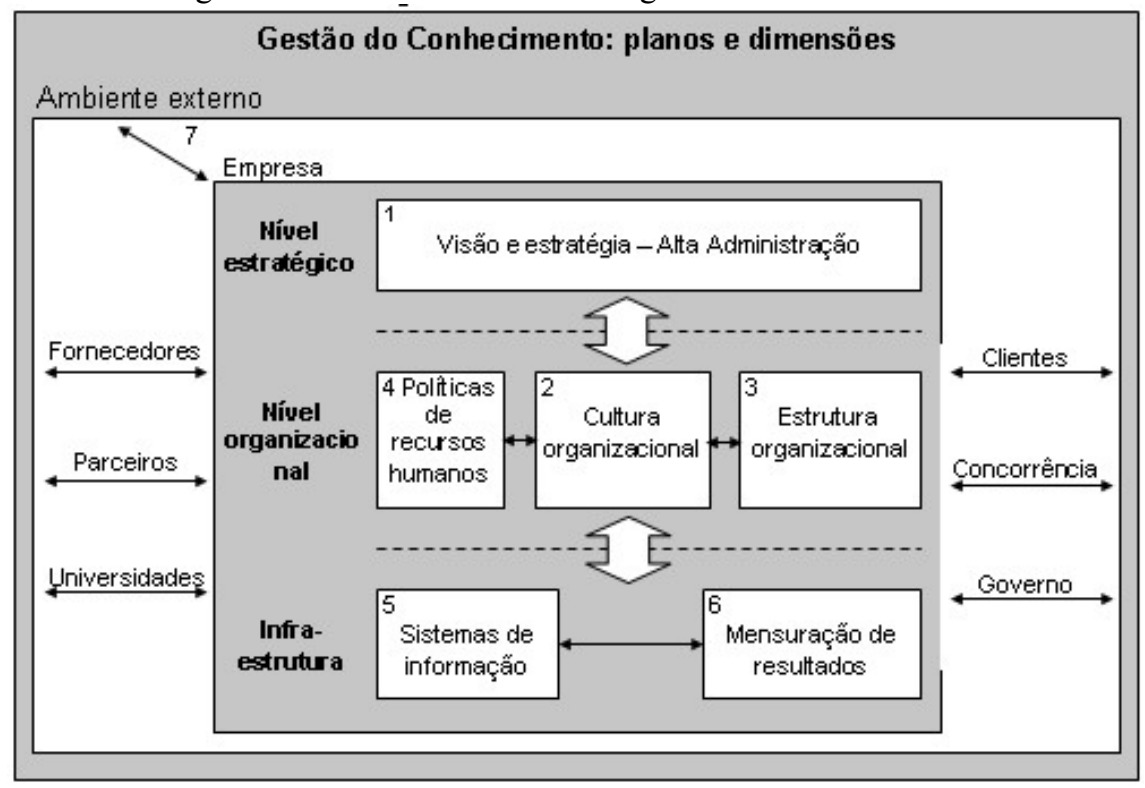

Adaptado de Terra (2000) 
Dentro da dimensão cultura, o autor enfatiza a inovação, experimentação e aprendizado contínuo. $\mathrm{Na}$ dimensão estrutura organizacional é destacado o trabalho em equipes multidisciplinares, comumente adotado em departamentos de $\mathrm{P} \& \mathrm{D}$ de empresas de grande porte. $\mathrm{Na}$ dimensão políticas de RH destacam-se as iniciativas de atrair e manter pessoas competentes, estimular comportamentos alinhados ao processo de aprendizado e adotar esquemas de remuneração associados à aquisição de competências. São discutidos na dimensão TI os sistemas de informação e a maneira como afetam os processos de geração, difusa e armazenamento de conhecimento.

Um outro modelo de referência para GC é apresentado por Mertins et al. (2003). Este modelo é composto de três níveis. O primeiro nível se refere às atividades empresariais de adição de valor, que deve ser o foco de todos os esforços de GC. No segundo nível são englobadas, de forma integrada, as atividades de gerar, armazenar, distribuir e aplicar o conhecimento dentro dos processos que geram valor dentro organização. Por último, o terceiro nível compreende as atividades empresariais que devem ser projetadas de maneira a aumentar a eficácia do processo de GC. São elas: gestão de pessoas, cultura empresarial, liderança, sistemas de controle, organização/papéis e, finalmente, TI (figura 3).

Segundo Mertins et al. (2003), a cultura deve ser definida levando-se em conta a estrutura organizacional e, também, a abertura e a autonomia das pessoas para favorecer a GC. Da mesma forma, em relação às políticas de $\mathrm{RH}$, ênfase é dada na competência para produzir resultados e feedback de maneira a aumentar a motivação dos colaboradores. Finalmente, as tecnologias de informação devem apoiar a comunicação, cooperação, coordenação e acesso adequado às fontes de conhecimento.

No entender dos autores do presente trabalho, as atividades centrais do processo de GC (geração, armazenamento, distribuição e uso do conhecimento) constituem elementos-chave do compartilhamento do conhecimento. 
Figura 3 - Processos chave e dimensões de projeto da gestão do conhecimento.

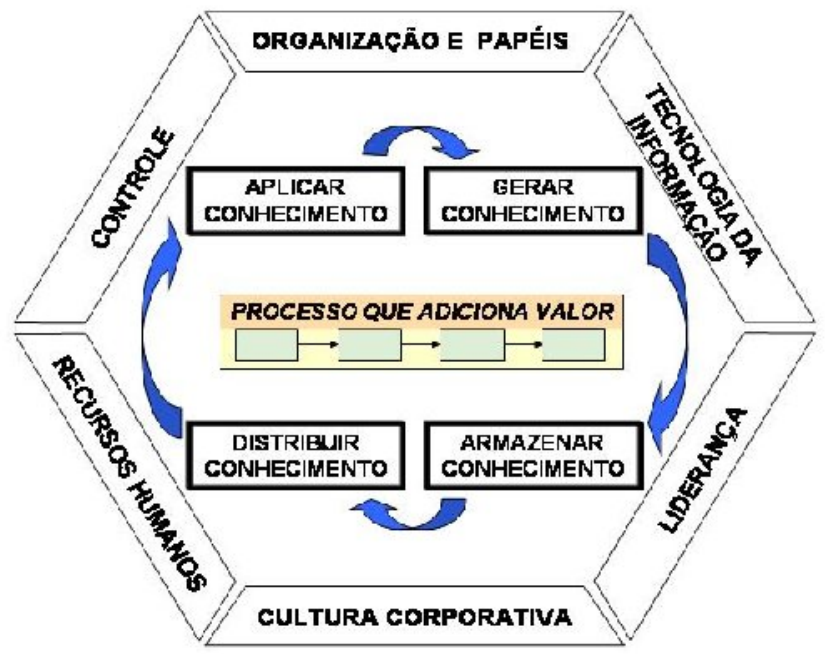

Fonte: Adaptado de Mertins et al. (2003).

Enfocando especificamente áreas industriais de P\&D, o artigo de Ambrecht et al. (2001) apresenta um estudo realizado em 19 empresas, reconhecidamente líderes e inovadoras nas práticas de GC, tais como: 3M, Dow Chemical, DuPont, Sandia Labs., Unilever, entre outras. A partir desta pesquisa foi gerado um modelo para o fluxo de conhecimento no processo de P\&D.

Neste modelo é apresentado, esquematicamente, o ciclo de transformação de conhecimento em resultados para a empresa e, também, são identificados três facilitadores do fluxo de conhecimento: cultura, infra-estrutura e tecnologia da informação, como mostrado na figura 4.

Figura 4 - Modelo simplificado de fluxo de conhecimento em áreas de P\&D.

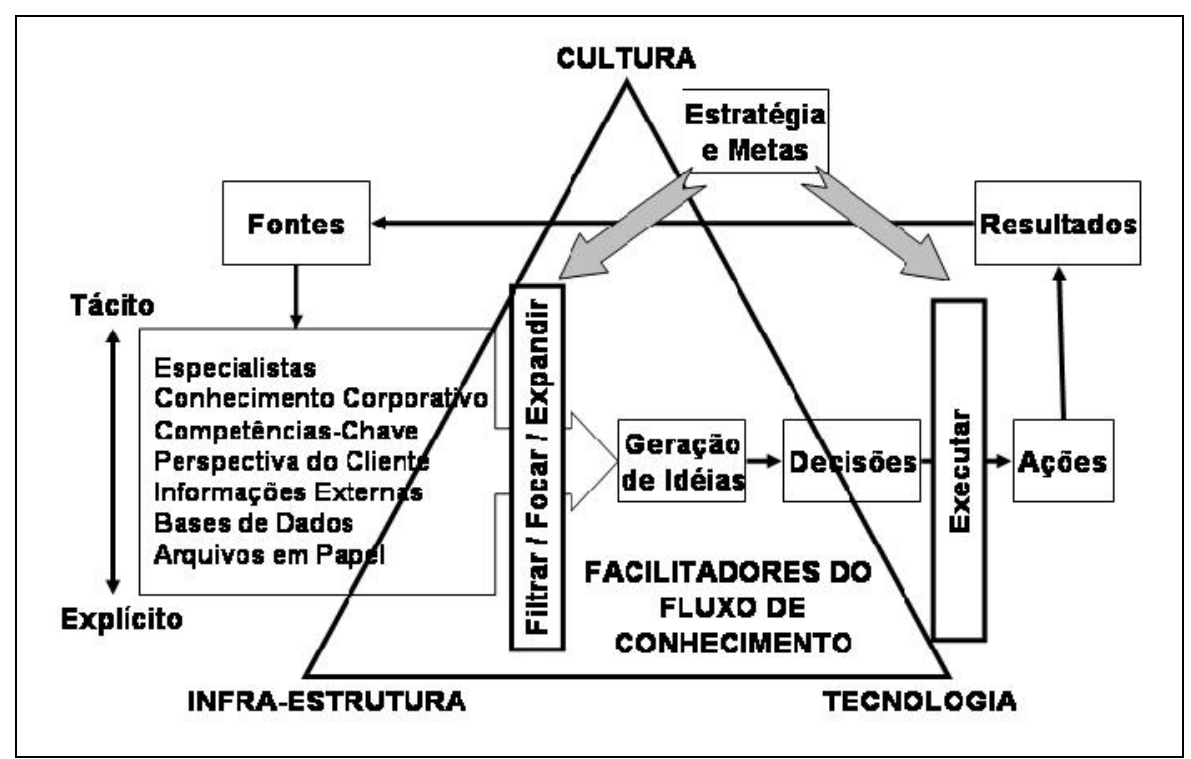

Adaptado de Ambrecht et al. (2001)

Esses facilitadores têm grande impacto nos processos de criação, aquisição e transferência de conhecimento empresarial visando à consecução dos objetivos do negócio. 
O facilitador cultura é o mais comumente citado e compreende o desenvolvimento de valores culturais que incentivem a criação e compartilhamento do conhecimento. Segundo Ambrecht et al. (2001), há um reconhecimento geral da necessidade de encorajar e facilitar a interação, colaboração, ensino e aprendizado entre os empregados.

Infra-estrutura refere-se ao impacto da gestão do conhecimento nas estruturas organizacional e física da empresa. Quanto mais horizontal, aberta e fluida for a estrutura organizacional melhor para o compartilhamento do conhecimento.

Ferramentas de TI, como computadores e estações de trabalho, são comumente citadas como uma base necessária para um ambiente colaborativo. Da mesma forma, e-mails, intranets e sites são quase universalmente citados como meios para estimular e facilitar o compartilhamento e acesso ao conhecimento (AMBRECHT et al., 2001).

Ambrecht et al. (2001) também destacam em seu trabalho as práticas que contribuem para o fluxo de conhecimento. Estas práticas foram categorizadas em três conjuntos:

a) interação pessoa - pessoa;

b) construção e transferência informal de conhecimento e

c) treinamento tanto para novos empregados como para antigos com novas atribuições.

\subsection{Práticas e Ferramentas de GC Encontradas na Literatura}

No trabalho de Guimarães, Lamas e Boscolo (2007) é apresentado um levantamento das práticas e ferramentas de GC identificadas na literatura, mostrando, de forma geral, o que tem sido feito para gerir o conhecimento nas empresas.

Neste trabalho é enfatizado que apesar de não haver um modelo único de implementação de GC ou uma receita pronta a ser seguida, existem algumas práticas e ferramentas de GC que são continuamente mencionadas e recomendadas pelos artigos e livros que tratam deste tema:

a) Trabalhar junto à alta diretoria para ter o apoio dos vice-presidentes e diretores. Os desafios são muitos e a alta administração precisa estar totalmente envolvida neste processo, desde o início;

b) Ter o mapeamento das habilidades e competências de cada funcionário, identificando as experiências passadas, os conhecimentos adquiridos, as lições aprendidas e os anseios profissionais e pessoais. Este mapa permitiria identificar as pessoas-chave na empresa, traçar planos para elas e, conseqüentemente, para os departamentos relacionados. Como mencionado anteriormente as pessoas são peças fundamentais nas estratégias de GC; 
c) Trabalhar para aumentar a conectividade entre as pessoas, cultivando o relacionamento entre elas. Empatia leva à confiança que leva ao compartilhamento natural do conhecimento;

d) Aperfeiçoar o layout dos escritórios. Uma área de convivência é fundamental para que as pessoas tenham um local neutro para se encontrar e trocar idéias. $\mathrm{O}$ ambiente contribui bastante para a efetiva troca de opiniões e de conhecimento;

e) Um programa de mentores e um programa de incentivo aos especialistas internos e externos (algumas empresas chamam estas pessoas de "gurus") é algo continuamente recomendado pela literatura. Estas duas entidades fazem com que os conhecimentos não facilmente mensuráveis sejam trocados e que as pessoas mais novas e menos experientes tenham acesso fácil aos especialistas;

f) Políticas de RH são muito importantes, como por exemplo, a forma como as contratações são realizadas, os meios para se identificar e reter os talentos e as políticas de remuneração e reconhecimento ao trabalho das pessoas;

g) Incentivar a geração de idéias, criando uma cultura de inovação na empresa. As pessoas devem se sentir valorizadas por darem e compartilharem suas idéias;

h) Incentivar a participação ativa dos colaboradores em congressos e seminários. Estes eventos são excelentes para a troca de experiências e o aumento de networking;

i) Implementar ferramentas adequadas de TI. Os Portais Corporativos têm sido amplamente utilizados atualmente e muitas empresas têm otimizado suas operações a partir da implementação destas aplicações. Intranet com navegação amigável, ferramentas de busca eficientes, sistemas de integração de informações internas e externas, banco de dados de lições aprendidas e boas práticas, sistemas de mensagem instantânea, blogs, páginas amarelas, ambientes virtuais para fóruns de discussões e universidade corporativa são alguns exemplos de ferramentas mencionadas pela literatura disponível.

\subsection{Categorização das Práticas e Ferramentas}

Para permitir melhor a análise dos dados provenientes da literatura, foram propostas quatro categorias para as práticas e ferramentas de GC. Estas categorias foram definidas tendo como base os modelos de GC e as práticas e ferramentas apresentadas capítulo 2.2, levando-se em conta os objetivos e filosofias centrais de cada prática ou ferramenta. Pode haver ferramentas e práticas que se enquadram em mais de uma categoria, porém, procurou-se escolher a característica mais influente em cada item citado.

As categorias foram assim denominadas: 
a) Tecnologia da Informação - Nesta categoria foram agrupadas as ferramentas usadas no gerenciamento de informações. Exemplos: Banco de dados de lições aprendidas e melhores práticas, ferramentas de busca, portais corporativos, sistema de e-mail e de mensagem instantânea, páginas amarelas;

b) Processos, Estrutura e Valores - Mostram como a empresa é. Isto é: o que valoriza, seu modo de agir interna e externamente e, também, como está organizada - desde suas instalações até o organograma. Exemplos: Celebrações, Cultura de inovação, Fomento à prática do diálogo, Layout voltado ao compartilhamento do conhecimento, Mapeamento e automatização de processos, Processo de sugestões;

c) Gestão de Pessoas - Como a empresa gerencia seu capital humano. Esta categoria também poderia ser uma subdivisão de "Processo, Estrutura e Valores", porém, decidiu-se dar maior ênfase ao gerenciamento do capital humano em uma categoria à parte. Exemplos: Política de identificação, contração e retenção de talentos. Avaliação e pagamento por competências, Mapas de habilidades dos funcionários, Plano de sucessão, Política de recompensas e premiações;

d) Compartilhamento do Conhecimento - Esta categoria agrupa práticas que favorecem e/ou controlam o fluxo de conhecimento dentro da empresa e, também, da empresa com outras instituições. Exemplos: Comunidades de prática, comunidades virtuais, políticas de publicação e participação em eventos especializados, programa de especialistas internos e externos, programa de mentores e coaching, universidades corporativas e programas de treinamento.

\section{Fases da Pesquisa}

a) Levantamento dos modelos, práticas e ferramentas GC citados na literatura: Foi efetuada pesquisa bibliográfica para se identificar ferramentas e práticas dos modelos de GC mais comumente utilizadas para gestão do conhecimento;

b) Divisão das práticas e ferramentas de GC em categorias: As práticas e ferramentas de GC encontradas na literatura foram divididas em categorias. Tais categorias também foram usadas para classificar as práticas e ferramentas indicadas pelos entrevistados;

c) Seleção das empresas e pessoas a serem entrevistadas: Para o estudo de caso, foram selecionadas três empresas que atuam no Brasil, considerando sua estrutura de P\&D e o grande potencial para o desenvolvimento de estratégias na área de gestão do conhecimento. Tratam-se de líderes em seus segmentos de atuação. Foram entrevistadas pessoas ligadas aos departamentos responsáveis por $\mathrm{P} \& \mathrm{D}$;

d) Condução das entrevistas: As entrevistas foram conduzidas pessoalmente ou por telefone. Antes das entrevistas, ocorreu uma conversa inicial sobre o tema, explicando brevemente 
os conceitos elementares de GC e mencionando algumas das práticas e ferramentas muito difundidas atualmente na grande maioria das empresas. As questões que serviram de referência aos entrevistados e entrevistadores foram:

“Quais são as práticas e ferramentas de GC utilizadas pela sua empresa?”

"Descreva sucintamente cada uma delas".

e) Análise das informações coletadas nas entrevistas: As práticas e ferramentas citadas durante as entrevistas foram classificadas à luz de semelhante categorização realizada com os dados de literatura (item b). Além disso, foram feitas comparações entre as práticas e ferramentas de GC adotadas pelas empresas analisadas.

\section{Resultados}

São apresentados, a seguir, os resultados das pesquisas realizadas com as três empresas denominadas como Alfa, Beta e Gama, para preservar a identidade das mesmas (GUIMARÃES et al., 2007).

\subsection{Empresa Alfa}

A empresa Alfa atua em um segmento tecnológico altamente competitivo há mais de 100 anos e conta com vários centros de engenharia espalhados pelo mundo. No total são mais de 10.000 engenheiros trabalhando com pesquisa e desenvolvimento, interagindo diariamente com outros engenheiros, dentro e fora de seus centros de desenvolvimento.

- Estrutura do Setor de P\&D: Como mencionado anteriormente, a empresa Alfa conta com vários centros de engenharia espalhados pelo mundo. A área diretamente responsável pelo desenvolvimento dos novos produtos é a Engenharia de Produtos, mas existem outros departamentos envolvidos neste processo.

A Engenharia de Produtos é responsável por capturar dos departamentos de Maketing e Design as características esperadas para o novo produto e materializá-lo de forma a obter, além dos resultados de desempenho esperados, um custo competitivo. Vale mencionar que a engenharia desta empresa trabalha não somente com novos produtos, mas também com projetos de melhoria de produtos correntes.

- Perfil dos Entrevistados: Foram entrevistados 09 profissionais da área de Engenharia de Produtos. Destes, 08 atuam no centro de engenharia localizado no Brasil e 01 atua em um dos centros de engenharia localizados no exterior. Todos os respondentes trabalham na empresa há pelo 
menos cinco anos, atuantes na área de P\&D. Tratam-se de líderes de projeto e/ou engenheiros seniores reconhecidos dentro da empresa por suas capacidades gerencial e técnica.

a) Tecnologia da Informação: Intranet, Portal Corporativo, Ferramenta de Busca do Portal Corporativo, Sistema Repositório de Dados de Engenharia, Sistema de Correio Eletrônico, Bancos de Dados Baseados em Lotus Notes, Drives Compartilhados, Sistema de Publicação de Informações, Sistema de Mensagem Instantânea, Banco de Dados de Memória Técnica, Lista Telefônica na Intranet, Repositório de Lições Aprendidas, Repositório de Boas Práticas, Catálogos de Solução de Engenharia, Web sites com Análises de Produtos dos Concorrentes;

b) Processos, estruturas e valores: Programa Interno de Sugestões. Política de Retenção de Informações, Estratégia de Centralização de Informações;

c) Gestão de Pessoas: para esta categoria não foi citada nenhuma ferramenta ou prática;

d) Compartilhamento do Conhecimento: Times Globais de Discussão Técnica, Fóruns Globais de Diretorias Técnicas, Sistema de Acompanhamento de Problemas Técnicos, Programas de Mentores, Programa de Treinamentos Internacionais, Universidades Corporativas.

\subsection{Empresa Beta}

A empresa Beta atua no setor de bens de capital há mais de 30 anos e, atualmente, é uma das líderes no seu segmento. Nesta empresa a pesquisa e o desenvolvimento tecnológico são fundamentais para que seus produtos se tornem cada vez mais atrativos e competitivos, uma vez que, no mercado em que atua, os produtos têm elevadas exigências de desempenho e segurança.

A pesquisa e o desenvolvimento têm foco tanto nos processos quanto nos produtos e serviços, visando: redução de custos e melhoria da qualidade, além de redução dos custos operacionais dos clientes.

- Estrutura do Setor de P\&D: As atividades de pesquisa e desenvolvimento são responsabilidades da área de Desenvolvimento Tecnológico. Suas principais atribuições são:

a) Efetuar estudos conceituais e pré-projeto de novos produtos;

b) Capturar, armazenar e distribuir informações tecnológicas relativas ao mercado de atuação da empresa;

c) Coordenar cooperações da empresa com entidades de ensino e pesquisa e, também, fornecedores;

d) Coordenar os projetos de desenvolvimento tecnológico. 
A Engenharia participa ativamente nos projetos de desenvolvimento tecnológico, desde a prospecção e elaboração de orçamentos e cronogramas, passando pela execução das etapas do projeto e divulgação dos resultados obtidos. Com isso, as informações e conhecimentos adquiridos ficam disponíveis para consulta e as inovações em materiais, processos e projetos podem ser incorporados aos produtos da empresa.

- Perfil dos Entrevistados: As informações sobre as ferramentas usadas em P\&D para gestão do conhecimento na empresa Beta foram obtidas através de entrevistas com 6 profissionais das áreas de Engenharia e Desenvolvimento Tecnológico. Todos ocupam cargos de gerência ou liderança e trabalham há mais de cinco anos na empresa.

\section{- Práticas e Ferramentas Categorizadas:}

a) Tecnologia da Informação: Intranet, Sistema Integrado de Bibliotecas, Portal Corporativo, Arquivo de Relatórios Técnicos, Sistema de Correio Eletrônico, Bancos de Dados, Drive Compartilhado para cada Departamento, Drive Compartilhado entre Departamentos.

b) Processos, Estruturas e Valores: Programa Interno de Sugestões.

c) Gestão de Pessoas: para esta categoria não foi citada nenhuma ferramenta ou prática.

d) Compartilhamento do Conhecimento: Programa de Trainees, Treinamentos Internos, Fóruns Internos de Discussões Técnicas e Relatórios de Participação em Congressos.

\subsection{Empresa Gama}

A empresa Gama é uma companhia de tecnologia diversificada com presença mundial em vários mercados, como os de consumo, cuidados com a saúde, industrial, produtos e serviços para segurança e transportes. É uma empresa que tem como característica a cooperação entre as suas subsidiárias, em pesquisa, processos de produção e propaganda dos produtos.

Tem operações em mais de 60 países, vende seus produtos em quase 200 países e conta com mais de 50.000 funcionários no mundo todo.

- Estrutura do Setor de P\&D: Sua área de P\&D está organizada em seis grupos de negócios, os quais compartilham recursos tecnológicos, de manufatura, de marketing e outros, aumentando sua velocidade e eficiência para atender clientes em vários segmentos de mercado.

- Perfil do Entrevistado: Foi entrevistado o Diretor responsável por um importante departamento ligado à área de pesquisa e desenvolvimento no Brasil. Este profissional tem mais de dez anos de empresa.

- Práticas e Ferramentas Categorizadas: 
a) Tecnologia da Informação: Banco de dados de projetos, biblioteca técnica, programa "Notebook", Net-meeting.

b) Processos, estruturas e valores: Liberdade para pensar.

c) Gestão de Pessoas: Retenção de pessoas.

d) Compartilhamento do Conhecimento: Fóruns técnicos, feiras técnicas internas e troca de experiência internacional.

\section{Análise Comparativa os Casos}

Inicialmente, observa-se que as quatro categorias usadas na classificação das práticas e ferramentas encontradas na literatura também foram adequadas à classificação dos resultados obtidos em todas as entrevistas conduzidas.

Na tabela 1 são mostrados os porcentuais, por categoria, das ferramentas e práticas que os entrevistados apontaram em cada uma das empresas.

Embora não se tenha buscado representatividade estatística na quantidade de pessoas entrevistadas, considera-se que os resultados podem indicar algumas tendências ou preferências. Como pode ser visto na tabela 1 e reforçado graficamente a seguir, na figura 5 , a maior parte das ferramentas e práticas indicadas pelos entrevistados se refere à Tecnologia da Informação, seguida pelo Compartilhamento do Conhecimento. Este tipo de resultado (especialmente um maior foco em TI por parte das empresas) é coerente com a maioria das referências bibliográficas consultadas.

Também foi observado que os entrevistados das empresas Alfa e Beta não mencionaram práticas ou ferramentas relacionadas à categoria Gestão de Pessoas, enquanto que na empresa Gama, esta categoria foi citada. Processos, Estruturas e Valores foi uma categoria pouco mencionada nas três empresas.

Tabela 1 - Porcentagem das práticas e ferramentas de GC em cada categoria

\begin{tabular}{ccccc}
\hline Empresa & TI (\%) & $\begin{array}{c}\text { Compartilhamento } \\
\text { do Conhecimento } \\
(\%)\end{array}$ & $\begin{array}{c}\text { Processos, } \\
\text { Estruturas e } \\
\text { Valores (\%) }\end{array}$ & $\begin{array}{c}\text { Gestão de } \\
\text { Pessoas (\%) }\end{array}$ \\
\hline Alfa & 64 & 32 & 4 & 0 \\
Beta & 61 & 31 & 8 & 0 \\
Gama & 44 & 33 & 11 & 11 \\
\hline \multicolumn{5}{r}{}
\end{tabular}

Os perfís de distribuição apresentados acima evidenciam que os entrevistados das empresas Alfa e Beta se preocupam mais com aspectos operacionais de GC, enquanto que o entrevistado da empresa Gama apresenta uma preocupação mais estratégica. Isto pode ser decorrente da diferença 
entre os níveis hierárquicos dos entrevistados. Enquanto nas empresas Alfa e Beta foram contatados líderes de equipes e gerentes, na empresa Gama foi entrevistado um diretor.

Percebeu-se, também, que nas três empresas as iniciativas de gestão do conhecimento parecem ser, em grande parte, isoladas e não há uma preocupação corporativa com o tema. Isto é reforçado pelo fato de serem citadas muitas ferramentas e práticas ligadas à TI e ao Compartilhamento do Conhecimento, que são categorias nas quais as iniciativas locais podem ser levadas à diante com maior facilidade. As práticas ligadas tanto à Gestão de Pessoas como a Processos, Estruturas e Valores, em geral, têm maior abrangência na organização e dependem de iniciativas da alta gerência. Vale acrescentar que a empresa Gama apresenta uma maior estruturação da GC dentro do setor de P\&D, mas, ainda assim, a gestão do conhecimento parece não ser pensada de modo corporativo.

Figura 5 - Perfil de distribuição percentual das categorias de práticas e ferramentas de GC nas empresas Alfa, Beta e Gama.

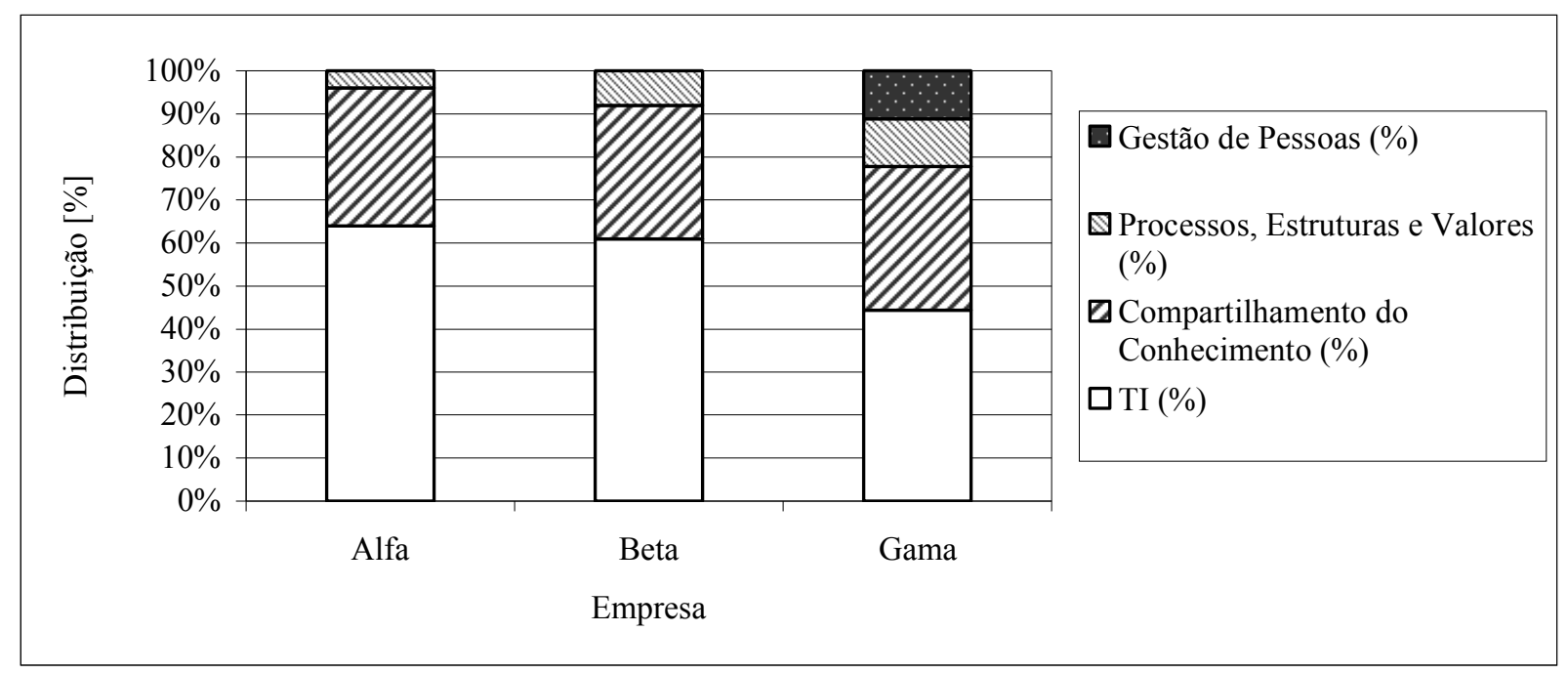

Fonte: Pesquisa de campo (2009)

Outro ponto a ser destacado é que, em todas as empresas, os entrevistados deram maior ênfase ao armazenamento, distribuição e compartilhamento do conhecimento. A geração, captação e aplicação (uso e reuso) do conhecimento foram pouco mencionadas.

\section{Conclusões e Comentários}

Esta investigação foi desenvolvida com o objetivo de identificar, à luz da bibliografia consultada, quais as práticas e ferramentas de GC mais freqüentemente lembradas por profissionais ligados às áreas de $\mathrm{P} \& \mathrm{D}$ de empresas onde inovação tecnológica tem peso significativo no negócio.

Partindo das práticas e ferramentas de gestão do conhecimento mais citadas na literatura, foram identificadas quatro categorias: 
- Tecnologia da Informação;

- Compartilhamento do Conhecimento;

- Processos, Estruturas e Valores;

- Gestão de Pessoas.

Essas categorias foram definidas de acordo com a filosofia central de cada prática ou ferramenta. Estas mesmas categorias também foram usadas para a classificação das ferramentas e práticas mais espontaneamente citadas pelos entrevistados das empresas, o que permitiu uma melhor comparação entre as informações coletadas nas entrevistas e a literatura.

Segundo as informações obtidas, condensadas na tabela 1, grande parte das ferramentas e práticas de GC nos departamentos de P\&D das três empresas parecem ter como base a tecnologia da informação e o compartilhamento do conhecimento, situação esta freqüentemente descrita e analisada pela literatura consultada.

Tomando como base a análise das entrevistas realizadas pelos autores, parece não existir preocupação em âmbito corporativo sobre o tema GC nas empresas analisadas. Os resultados da pesquisa indicam que parece haver apenas iniciativas isoladas dos respectivos setores de P\&D.

Chamou também a atenção dos autores o fato de que aspectos ligados à cultura organizacional e gestão de pessoas, embora reconhecidamente importantes na questão GC, são pouco lembrados pelos entrevistados.

Caso haja interesse em aprimorar a pesquisa, recomenda-se entrevistar mais pessoas, com especial atenção a diferentes níveis hierárquicos em cada empresa, com o objetivo de verificar se há diferentes percepções entre pessoas em cargos mais operacionais em comparação com cargos mais estratégicos.

\begin{abstract}
In the current context of global business, the effective management of intangible assets such as knowledge has become a competitive advantage. Both industries and R\&D organizations have shown interesting results due to the application of Knowledge Management (KM) principles to optimize the development of new products and processes. This paper aims to compare tools and practices of KM reported in the literature with those used in the areas of R\&D of three Brazilian large companies. Four categories of practices and tools of KM have been identified from the theoretical framework: a) Information Technology b) Sharing Knowledge, c) Processes, Structures and Values d) People Management. Sixteen R\&D professionals were interviewed and the information obtained was analyzed using the same categories identified in the literature. The results show that most of the tools and practices of KM in R\&D departments seem to be based on information technology and knowledge sharing. Although considered important in KM literature, aspects related to organizational culture and people management were not mentioned by the interviewees.
\end{abstract}

Key-words: Knowledge Management, practices, tools, R\&D. 


\section{Referências}

ARMBRECHT Jr, F.M.R. et al. "Knowledge management in research and development". Research-Technology Management, Virginia, p.28-48, jul. 2001.

GUimARÃES, A. A., LAMAS, J. E., BOSCOLO, P. G. Gestão do conhecimento em áreas de P\&D: estudo de caso em empresas brasileiras de grande porte. São Paulo, 2007. Monografia de MBA em Conhecimento, Tecnologia e Inovação - Fundação Instituto de Administração.

MARTINS, G. A.; LINTZ, A. Guia para elaboração de monografias e trabalhos de conclusão de curso. $1^{\mathrm{a}}$. ed., São Paulo : Atlas, 2000.

MERTINS, K., HEISIG, P., VORBECK, J. (org.) Knowledge management: concepts and best practices - 2a ed., Berlin : Springer-Verlag, 2003.

NONAKA I.; TAKEUCHI H. Criação de Conhecimento na Empresa, 16 a ed., Rio de Janeiro : Elsevier, 1997.

PRUSAK, L. Where did knowledge management come from?. IBM Systems Journal, v. 40, n. $2,2001$.

PRUSAK, L. Conferência: Produtividade do trabalhador do conhecimento. FEA - USP, São Paulo, 27 de março de 2006.

ROUSSEL, P. A., SAAD, K. N. BOHLIN, N. Pesquisa e Desenvolvimento: como integrar P\&D ao Plano Estratégico e Operacional das Empresas como Fator de Qualidade e Produtividade. São Paulo : Makron Books, 1992. 198 p.

TERRA, J.C.C. Gestão do conhecimento: o grande desafio empresarial. . São Paulo : Negócio, 2000.

TERRA, J.C.C.; GORDON, C. Portais corporativos: A revolução na gestão do conhecimento”. 5a ed., São Paulo : Elsevier, 2002.

TIDD, J., BESSANT, J.; PAVITT, K. Managing Innovation: Integrating Technological, Market and Organizational Change. Sussex : John Wiley \& Sons, 2001. 388p.

\section{Dados dos autores:}

Nome completo: José Eduardo Gonçalves Lamas

Filiação institucional: Empresa Brasileira de Aeronáutica S. A. - Embraer

Departamento: Aviação Executiva

Função ou cargo ocupado: Engenheiro de Estruturas e Materiais

Endereço completo para correspondência (bairro, cidade, estado, país e CEP): Avenida Brigadeiro Faria Lima, 2170 - Putim - S. J. Campos - SP - Brasil - 12227-901

Telefones para contato: (11) 7117-2403

e-mail:jose.lamas@embraer.com.br

Nome completo: Paulo Tadeu de Mello Lourenção

Filiação institucional: Empresa Brasileira de Aeronáutica S. A. - Embraer

Departamento: Desenvolvimento de Pessoas

Função ou cargo ocupado: Analista de RH

Endereço completo para correspondência (bairro, cidade, estado, país e CEP): Avenida Brigadeiro Faria Lima, 2170 - Putim - S. J. Campos - SP - Brasil - 12227-901 
Telefones para contato: (12) 3927-6284

e-mail:paulo.lourencao@embraer.com.br

Nome completo: Alexandre de Almeida Guimarães

Filiação institucional: General Motors do Brasil Ltda. - GMB

Departamento: Engenharia de Produto

Função ou cargo ocupado: Gerente de Engenharia

Endereço completo para correspondência (bairro, cidade, estado, país e CEP): Rua Xavier de Almeida, 1135, Ap 83, Ipiranga, São Paulo, SP, CEP 04211-001

Telefones para contato: (11) 4234-6000

e-mail: alexandre.guimaraes@gm.com.br

Nome completo: Pedro Geraldo Boscolo

Filiação institucional: Quattor Petroquímica S.A.

Departamento: Pesquisa e Desenvolvimento

Função ou cargo ocupado: Gerente de Tecnologia

Endereço completo para correspondência (bairro, cidade, estado, país e CEP): Rua Joaquim Floriano, 960 - Itaim Bibi - São Paulo - SP - Brasil - 04534-004

Telefones para contato: (11) 3707-6000

e-mail:pedro.boscolo@quattor.com.br

Nome completo: Isak Kruglianskas

Filiação institucional: Faculdade de Economia e Administração - FEA - USP

Departamento: Administração

Função ou cargo ocupado: Chefe de Departamento de Administração

Endereço completo para correspondência (bairro, cidade, estado, país e CEP): Av. Professor

Luciano Gualberto, 908 sala E-194 - Cidade Universitária - São Paulo - SP - Brasil - 05508-010

Telefones para contato: (11) 3818-4248

e-mail: ikruglia@usp.br

Recebido para publicação em: $31 / 08 / 2009$

Aceito para publicação em: 09/11/2009 